\title{
Reform of Teaching Mode on Subject - Mechanical Engineering Material- according to Requirement for 'Outstanding Engineer Plans'
}

\author{
Yinan Li a, ${ }^{,}$, Zilong Peng ${ }^{b}$ \\ College of mechanical engineering, Qingdao Technological University, Qingdao 266000, China \\ aliyinan2004@163.com, bpzlmail@163.com
}

Keywords: teaching method, Moocs, Flipped Classroom, project teaching method.

\begin{abstract}
In this paper, the innovative teaching method of subject- Mechanical Engineering Material is put forward in order to fulfill the requirement of 'Outstanding Engineer Plans'. Through the application of Moocs, flipped classroom and project teaching method in teaching 'Mechanical Engineering Material', the learning and innovation capacity of the students will be improved tremendously. First, this new attempt of teaching method is aimed to the students who are born after 1990 and have distinctive personality compared with the 'after 70s' and 'after 80s'. Second, the knowledge points are rearranged and categorized and the logical relationship among these points are cleared in order to come up with the application of Moocs, flipped classroom and project teaching method. Finally, the application of Moocs, flipped classroom and project teaching method in teaching 'Mechanical Engineering Material' are designed and put into effort with the diverse teaching modes including pre-class online course, class discussion and case based teaching.
\end{abstract}

\section{Introduction}

'Mechanical engineering material' is a professional basic subject for students who are majored in mechanical engineering and material science and technology. In this subject, taking the materials that mainly are used in mechanical engineering and processing for teaching objects, the relationships among the application, the chemical composition, the structure, the heating processing and the mechanical performance of these materials are elaborated thoroughly. And the teaching aim is that the students need to acquire the knowledge on the basic theories, the heating processing technique and the characteristic and the performance about the engineering materials. On this basis, the students also need to learn how to select the material reasonably according to the application environment and set out the machining process procedures properly. This subject is the basic for the successive subjects such as 'Mechanical Design' and 'Principle Mechanical', which plays an essential role in the subject system. The training objective of this subject is training the innovation capacity, practical capacity, analytic capacity and comprehensive engineering quality of the students. Therefore, it is necessary to reform the teaching method of this subject as there are some shortcomings in existing teaching method.

\section{Existent main problems and characteristics of education group}

\subsection{Existent main problems.}

In the existent content system of this subject, the selection and arrangement of the knowledge points don't break away from the traditional teaching design, the update rates of new materials, technologies and processes are tardy relatively and the innovations about contents in text books are not enough. All of these shortcomings make the existent teaching mode cannot meet the requirement of 'Outstanding Engineer Plans'. In addition, nowadays the main class pattern is that students are received the knowledges passively when the teacher is giving lessons in the classroom. In this way, both of the teachers and the students feel tired while the cultivation on comprehensive ability is way off the target. 


\subsection{Characteristics of education group.}

In this day and age, the students in the education group are born after 1990, who are called 'the 90s freshman'. Compared to the 'after 70s' and 'after 80s' these 90s freshmen has distinctive characteristics, which are included as follows. (1) The sources and acquiring ways of knowledge are not limited to the text books, and the other ways such as Internet, broadcasting or TV programs can provide plenty of knowledge for them. (2) The 90s freshmen have super reception capacity and independent learning ability of knowledge in a wide range of disciplines.

(3) The 90s freshmen have wide interests and incline to lose attention on one interest. It is hard for them to have deep thinking on a specific topic and insist on studying one subject. (4) The interest on one subject takes the first place when the $90 \mathrm{~s}$ freshmen is studying. If the teacher could not catch up with their attention, the 90 freshmen will lost the interest on this subject and the antagonistic psychology will be aroused in their minds, which interfere the further learning. Therefore, according to the learning characteristics of the 90 s freshmen, it is vital to conduct some reformations on teaching mode on subject- Mechanical Engineering Material especially in the contemporary environment.

\section{Reforming ideas and methods}

Through the application of Moocs (massive open on line course), flipped classroom and project teaching method in teaching 'Mechanical Engineering Material', the knowledge points in this subject will be rearranged, logical relationship among these knowledge points will be rebuilt and the comprehensive tasks on how to use the knowledge will be settled. After the teaching mode reformation, the knowledge system of this subject will be enhanced and the learning effect and practical ability of the students will be improved.

\subsection{Pre-class learning reformation.}

As the students have the different level of learning abilities it is unrealistic for them to grasp all of the contents that are taught in the classroom. Therefore in order to involve every student some teaching methods should be provided pre-class as follows. (1) Online education courses such as Moocs and APPs in smart phone need to developed and applied. Combined with the words, diagrams and flash the knowledge points are made in the form of video to exhibit on these Medias. (2) The students need to follow the relative Moocs and APPs and pay attention to the knowledge points before the class. (3) The key knowledge is needed to reminder for the students on these Medias before each class. And at the end of each online course the questionnaire about the reaction on the difficult points should be attached and the student should fill out the questionnaire in order to let the teacher master the preparation levels of each student.

Taking the knowledge point $\mathrm{Fe}-\mathrm{C}$ phase diagram for example, the online video or program on APPs is developed. According to the sequence of point-line-zone in phase diagram, the diagram can be illustrated thoroughly. The structure evolutions in every zone or every composition are designed into flashes, which are exhibited vividly to students and improve the learning efficiency.

\subsection{Rearranging the knowledge points and rebuilding the logical relationship among these knowledge points.}

The existing knowledge system is broken and recombined in order to form the new theme knowledge points that are suitable for Moocs and program in APPs. And the new knowledge system is divided into two parts: the basic theme knowledge points and the application knowledge points. The goal of master the basic theme knowledge points is making the students learn about the basic knowledge and the relative background and theory, including crystal of metals and phase structure, the metal crystallization, Fe-C phase diagram, the plastic deformation and recrystallization of metals, the transformation of iron during heating and cooling and the technology for heating processing. The goal of the application knowledge points is cultivating the students' ability to selection the proper materials according to the application condition and environment, including the mechanical failures and the selection of material for the machine parts. Through learning the application knowledge points the students will enhance the comprehension of basic knowledge and learn how to use these knowledge comprehensively. Furthermore, the innovation consciousness and ability is improved. 
The logical relationships among the knowledge need to clear. First, the main line of this subject is drawn out, which is ascribed as 'chemical composition+ heating processing - structure and organization - mechanical performance - application'. And the seemingly messy knowledge points are combined organically by this main line, which is extremely helpful for students clear frustration and master the transferable skill of knowledge. What's more, when the application knowledge points are teaching, the main line of this part also is ascribed as 'typical grades - main application mechanical performance requirement - function of chemical elements - heating processing procedure and the microstructure'. Fig. 1 is the schematic diagram of rearranged knowledge points. In this diagram, the elliptic icon means single knowledge point, the square icon means theme knowledge point, and the line means the logical relationships among these knowledge points.

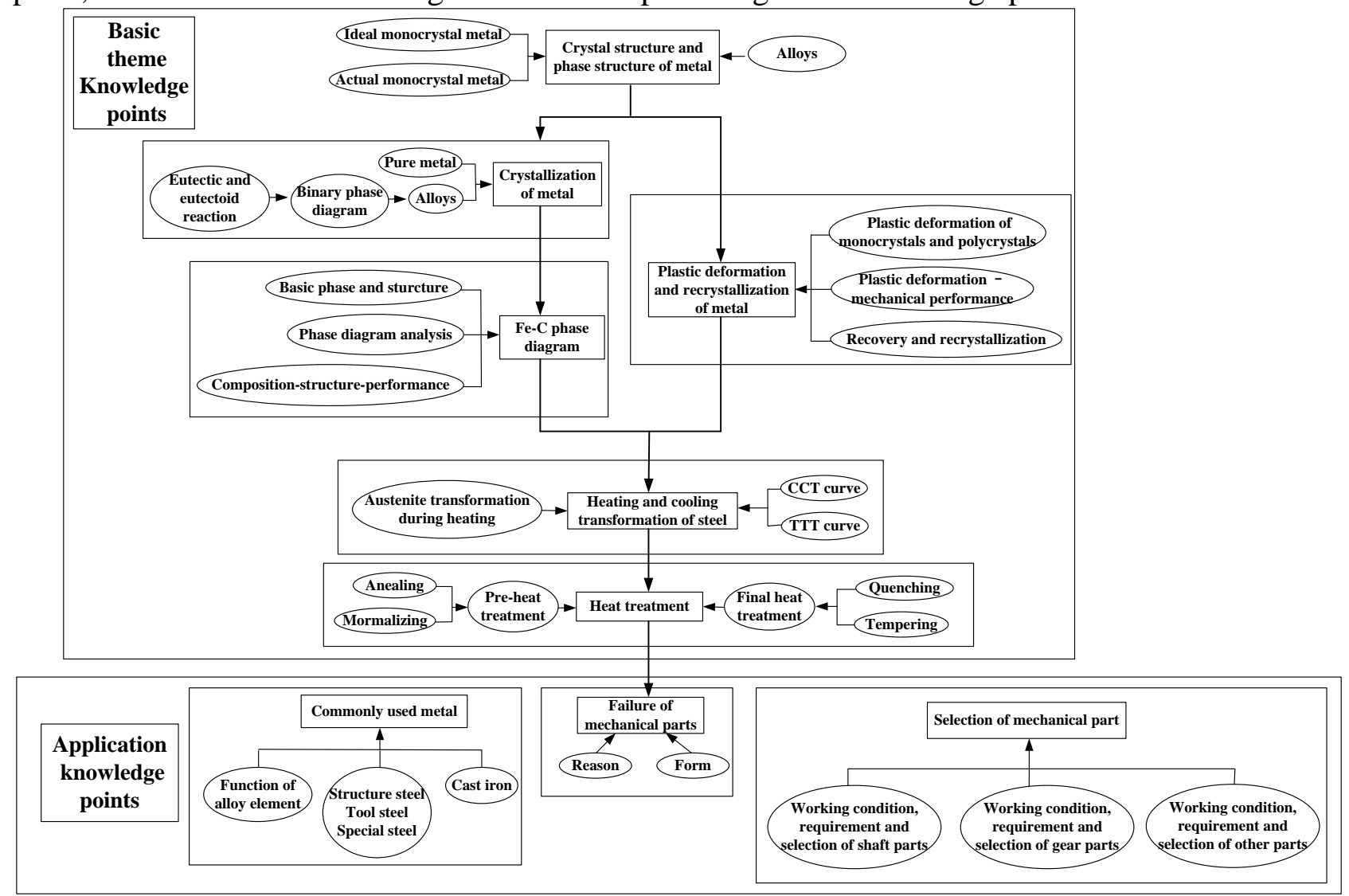

Fig. 1 Schematic diagram of the knowledge points

\subsection{Application of flipped classroom based on discussion teaching and case based teaching.}

Through the pre-class learning, the students have mastered some basic knowledge points, which prepare the basement and guarantee for building the flipped classroom. The flipped classroom aims to take the students as the major part and the teacher as the conductor, which means that in the flipped classroom the teacher' main task is helping and guiding the students to master the interior logical relationships of separated knowledge points and ensuring the students to build the extension of the knowledge points. When the students have some knowledge equipment, the teaching method such as the class discussion and the comprehensive assignment will be adopted to enhance the master of the knowledge points.

Taking the knowledge point-the influence of alloy elements in steels on mechanical performance for example, the case based teaching can intrigue the students' thinking and understanding on this point. In this section, the Titanic is used as the example of case teaching. As the majority of students had seen this film they will be curious about the submergence of this gigantic ship when the teacher analysis the reason on the aspect of material science. The Titanic was called 'un-sinking ship' at that time as the cabins were designed and manufactured separately, which means even though one of these cabins is leaked by the exterior strike the other cabins would not be leaked at the same time. Therefore, it takes several days to sink when this huge ship strikes with the other ships or iceberg. However, this gigantic ship was sink into the deep ice sea on its first voyage, which is the most miserable and 
unforgettable tragedy in the twentieth century. When realizing the information, the students are so curious about the cause of this tragedy. And then the teachers discover the mystery from the aspect of material science: The Titanic was made of a kind of steel with high sulfur, which could not afford the exterior strike in low temperature. When the ship dumped into the iceberg, a large amount of fragile fractures were taken place, which induces ice water flooding into the cabins and ship sinking quickly. Through the analysis of the case teaching, the students show great interest to the knowledge point and come to realize the importance of alloy elements to the steel. Therefore, the flipped classroom including class discussion and case based teaching will intricate the students' thirsty of knowledge and improve their studying efficiency.

\subsection{Attempt of project teaching method aiming to cultivate innovation.}

The project teaching method includes following steps.

First, the project design. When doing this task, several factors need to be considered thoroughly: (1) whether the project can help the students apply the learned knowledge. (2) Whether the project can induct the students learning new knowledge independently. (3) Whether the project can play the role in connecting the former and following content. (4) Whether the project can intrigue the interest of the students to learn. (5) Whether the project can improve the communication and cooperation among the students during project conducting course. (6) Whether the project can promote the students using the learned academic knowledge into practice. (7) Whether the project has the integrity which means that the students can provide the complete products such as a machine or a flash at the end 91 of the project.

Second, the project assignment. In this section, there are several steps need to conduct: (1) Establishing the scenario. The scenario means that the teaching environments in project teaching method. For instance, when learning the steel and iron, the students are required to find some metals that are familiar to them, including the key, the steel wire or the saw and then to analysis the characteristic of the metals. (2) Assigning the task. The students are divided into several groups and each group has independent task. For example, the studying group can select the metals made up to different mechanical parts found in the laboratory, such as axis parts, gears, cutting tools, and the mould. Then aiming at a given mechanical parts, the students group will study and analysis this kind of metal according to the main line, which is ascribed as 'chemical composition theating processing - structure and organization - mechanical performance - application'. (3) Learning independently. After the introducing the working environment and requirement of mechanical parts from teacher, the students need to contrive the basic design ideas through the group discussion. The teacher needs to help students in finding, collecting and facilitating the studying resources. (4) Learning cooperatively. When assigning the task to the students in the project group, the teacher should distribute the task to the proper student after considering the personality of each student. In this way, every student in the project groups will play his/her greatest effort to finish the project. (5) Settling the problem. When finishing the project, the students will gather together to find the problem they met during the process. Through the discussion and brain storm, the students will recognize the deficiencies of their knowledge system and find the better solution to the problem. (6) Strengthening and improving the knowledge. With the accomplishment of the project, the students will learn how to improve their interior abilities by absorbing the knowledge. And they will have the ability to build up their own knowledge system by connecting the separated knowledge pints with a logical line and then have the ability to introspection and innovation, which is play a pivotal role in their future career.

\section{Summary}

Through the reformation of teaching mode of subject- Mechanical Engineering Material, the learning enthusiasms of the students are inspired and the studying efficiency is improved. Through the application of Moocs, flipped classroom and project teaching method, the learning and innovation capacity of the students will be improved tremendously. First, the changing of teaching method aims at the students who are born after 1990 and have distinctive personality compared with the 'after 70s' and 'after 80s'. Second, the knowledge points are rearranged and categorized and the logical relationship among these points are cleared for the sake of adapting to the application of Moocs, 
flipped classroom and project teaching method. Finally, the application of Moocs, flipped classroom and project teaching method in teaching 'Mechanical Engineering Material' are designed and carried out with the diverse teaching pattern including pre-class online course, class discussion and case based teaching.

\section{Acknowledgements}

This work was supported by the Project of Shandong Province Elite University Construction (MX4-020, MX4-053).

\section{References}

[1]. X. Z. Xu. Research on teaching material construction of "Electrical Engineering and Electronics" based on outstanding engineers plan The International Conference on Biotechnology, griculture, Environment and Energy. 2014.244-247.

[2]. C. Yang. Z. Li. A Tentative Exploration of the Educational Training Mechanism of Outstanding Engineers' Mineral Processing Engineering Major. 2015 International Conference on Social Science,Education Management and Sports Education. 2015.79-82.

[3]. H. Chen, Z. H. Tan. Discussion on "Outstanding Engineers" Training Program for Information Security Major in China. The 2012 International Conference on Future Computer Supported Education. 2012:877-881.

[4]. P. H. Zhu, J.Y. Wu. On Practice Teaching System of "A Plan for Educating and Training Outstanding Civil Engineers". 2013 2nd International Conference on Education Reform and Management Innovation. 2013:226-229.

[5]. S.X. Wang, G.S. Liu. Course Teaching Design for Mechanical Engineering Materials under the Outcome-based Education Theory. 2014 4th International Conference on Applied Social Science. 2014:301-307.

[6]. M.Q. Xue. Application of Multimedia Technology in Mechanical Engineering Material Teaching of Vocational College. 2011 International Conference on Frontiers in Computer Education. 2011:26-30. 